\title{
Bilingualized Dictionaries with Special Reference to the Chinese EFL Context
}

\author{
Yuzhen Chen, Department of Foreign Languages, \\ Putian University, Fujian, P.R.C. (spring1918@yahoo.com.cn)
}

\begin{abstract}
As a type of dictionary with huge popularity among EFL learners in China, the bilingualized dictionary (BLD) deserves more academic and pedagogical attention than it receives nowadays. This article gives an overview of the BLD within the framework of dictionary research, including dictionary history, dictionary typology, dictionary criticism and dictionary use. It first traces, with a special reference to the Chinese EFL context, the origin and historical development of this type of dictionary, and then proposes several approaches to its classification. The strengths and weaknesses of the BLD are evaluated and its role in language pedagogy discussed, followed by an extensive review of the empirical studies of BLD use. Finally, further areas of BLD research are also suggested. It is hoped that such an overview would kindle more research interest in BLDs which is relevant to language pedagogy, dictionary use instruction and lexicographic practices.
\end{abstract}

Keywords: LEXICOGRAPHY, BILINGUALIZED DICTIONARIES, MONOLINGUAL DICTIONARIES, BILINGUAL DICTIONARIES, ORIGIN, HISTORICAL DEVELOPMENT, DICTIONARY TYPOLOGY, DICTIONARY CRITICISM, DICTIONARY USE, CHINESE EFL CONTEXT

Opsomming: Verklarende woordeboeke met 'n tweetalige dimensie met spesiale verwysing na die Chinese EVT-konteks. As ' $n$ tipe woordeboek wat enorme gewildheid geniet by EVT-aanleerders in China, verdien die verklarende woordeboek met vertalings (bilingualized dictionary of BLD) meer akademiese en opvoedkundige aandag as wat dit deesdae ontvang. Hierdie artikel gee 'n oorsig van die BLD binne die raamwerk van woordeboeknavorsing, insluitende die geskiedenis van woordeboeke, woordeboektipologie, woordeboekkritiek en woordeboekgebruik. Dit skets eers, met spesiale verwysing na die Chinese EVT-konteks, die oorsprong en historiese ontwikkeling van hierdie tipe woordeboek, en dan word verskeie benaderings vir die klassifikasie daarvan voorgestel. Die sterk punte en swakhede van die BLD word beoordeel en die rol daarvan in die taalpedagogiek word bespreek, gevolg deur 'n uitvoerige oorsig oor die empiriese studies van die gebruik van die BLD. Ten slotte word verdere gebiede vir BLD-navorsing ook voorgestel. Daar word gehoop dat so 'n oorsig meer belangstelling sal wek in navorsing oor BLD's, wat relevant is vir taalpedagogiek, die aanleer van woordeboekgebruik en leksikografiese praktyk.

Sleutelwoorde: LEKSIKOGRAFIE, VERKLARENDE WOORDEBOEKE MET 'N TWEETALIGE DIMENSIE, EENTALIGE WOORDEBOEKE, TWEETALIGE WOORDEBOEKE, OORSPRONG, HISTORIESE ONTWIKKELING, WOORDEBOEKTIPOLOGIE, WOORDEBOEKKRITIEK, WOORDEBOEKGEBRUIK, CHINESE EVT-KONTEKS 


\section{Introduction}

The most distinctive feature of bilingualized dictionaries (henceforth BLDs) is their entry formula: headword + definition in the same language + gloss in a different language (James 2000), as in English-Chinese BLDs ${ }^{1}$. Such dictionaries are hybrids in nature and seen as "compromise products" between monolingual and bilingual dictionaries, combining the advantages of both (Hartmann 1993). In other words, BLDs are "neither absolutely monolingual nor absolutely bilingual - they are both at once" (Pujol et al. 2006: 198). Many dictionary use surveys in China have shown that BLDs are by far the most popular paper dictionaries with Chinese EFL learners (e.g. Yu 1999, Fan 2000, Lang and Li 2003, Chi 2003, Thumb 2004, Shi and Chen 2007, Li 2009, Chen 2007, 2011a). However, the commercial success of BLDs has not prompted extensive and in-depth research into this type of dictionary. Despite a few studies about the theoretical and practical issues, generally, there remains a lot to be explored in other areas of BLD research, particularly in dictionary use research. Given the prevalence of BLD use in the Chinese EFL context, it is necessary to give an overview of this type of dictionary within the general framework of dictionary research. Such an investigation is also relevant at the world level, as BLDs seem to enjoy only a marginal status in the western lexicographical circle.

\section{BLDs: past and present}

\subsection{Bilingualization as a genre}

According to Hartmann and James (2000: 14), the BLD is a type of dictionary based on a monolingual dictionary in which entries have been translated in full or in part into another language. Actually, this definition covers only one category of BLDs, for there are others which are not adapted from a monolingual work but written by the same dictionary writer(s) like the English-Chinese BLDs compiled independently by Chinese scholars. In the broadest sense, BLDs are dictionaries which contain on the right-hand side of an entry the corresponding information in both L1 and L2 to explain the entry headword on the left. This type of dictionary combines features of the monolingual dictionary (e.g. L2 $\rightarrow$ L2 formulation) with the bilingual dictionary (e.g. L2 $\rightarrow$ L1 equivalence) in a composite entry formula (e.g. L2 $\rightarrow$ L2 + L1), and therefore is also called a hybrid.

Compared with monolingual and bilingual dictionaries, BLDs seem to have a relatively short history. Yet long before the emergence of modern BLDs, some features of this genre had already appeared (Chen 2011b). A Timely Gem Dictionary Tangut-Chinese (《番汉合时掌中珠》), which was compiled in 1190 by Gulemaocai (骨勒茂才), an ethnic of Dangxiang nationality, was believed to be the world's earliest bilingual glossary with both source and target language explanations (Yong and Peng 2008: 377-378). Archaeological evidence shows 
that this dictionary, engraved in wood tablets, contains 414 entries, each of which is arranged in four columns from the right to the left in the order of a) the Chinese phonetic notation of the Tangut word, b) the Tangut word, c) the Chinese equivalent to the Tangut word, and d) the Tangut phonetic notation of the Chinese equivalent. The dictionary can be seen as a very early precursor to the BLD as it includes both L1 information and its counterpart in L2, though only at the phonological level. According to Osselton (1995: 128), the first bilingualized English dictionary intended for language learners is Nathan Bailey's Orthographical Dictionary (1727) which provides French and Latin glosses for English headwords.

It should be pointed out that before the advent of modern monolingual learner's dictionaries, BLDs, originally conceived of as antidotes to bilingual dictionaries, had already been very popular in some Asian countries such as Bengal and India. As noted by James (2000: 136), the motivation for the development of a monolingual learner's dictionary was in reaction to the growing popularity of BLDs in India in the early years of the 20th century. However, as it turned out, the monolingual learner's dictionary began to be bilingualized a couple of decades later. The difference is that most modern BLDs provide definitions which have some linguistic basis insofar as the lexical selection is concerned (James 2000: 136). The first bilingualized version of modern monolingual learner's dictionary (English-Bengali) appeared in 1958. In 1970, the first English-Chinese bilingualized product of Oxford Advanced Learner's Dictionary $(O A L D)$ was published in Taipei, later in Hong Kong, followed by similar adaptations in other languages such as Hindi, Greek, Italian, Spanish, Norwegian, Japanese, and Portuguese (Hartmann 1994, Marello 1998). From the late 1970s onward, the Kernerman Publishers of Tel Aviv, Israel, have produced a special kind of BLDs, known as semi-bilingual dictionaries which provide simple and short glosses for English definitions to speakers of Hebrew, Arabic and some other European, Asian and African languages².

\subsection{BLDs in China}

In China, the early 20th century saw the publication of many English-Chinese BLDs. The Commercial Press English and Chinese Pronouncing Dictionary (《华英音韵字典集成》), published in 1902, is believed to be the first of its kind compiled by Chinese scholars (Wang 2010), followed by others such as An English-Chinese Standard Dictionary (《英华大辞典》1908), The English-Chinese Dictionary (《英汉双解词典》1912), and The Practical English-Chinese Dictionary (《实用英汉双解词典》1936). There were also a few early bilingualized versions of American collegiate dictionaries such as Modern Dictionary of the English Language with Anglo-Chinese Explanation (《新式英华双解词典》 1919) and Webster's Collegiate Dictionary with Chinese Translation (《英汉双解韦氏大学字典》1924). In recent decades, the Chinese dictionary market has been flooded with a wide variety of BLDs, most of which have been adapted from English learner's dictionaries, particularly the "Big 
Five". New translated versions would always follow shortly after new editions of these major learner's dictionaries came out. There are also some BLDs based on American collegiate dictionaries such as Random House Webster's Dictionary of American English, Webster's New Collegiate Dictionary and The American Heritage Dictionary for Learners of English. In addition to learner's dictionaries, there are also other types of BLDs such as DK Oxford Illustrated English-Chinese Dictionary, McGraw-Hill Dictionary of Scientific and Technical Terms, Oxford Dictionary of Economics, and Longman Dictionary of Language Teaching and Applied Linguistics, to name but a few.

The category of BLDs that are designed independently by Chinese scholars continue to emerge and serve a wide range of users, such as A Multi-functional Dictionary for College English Teaching and Learning, A New English-Chinese Dictionary with Multiple Usage, and Multi-functional English Dictionary with Chinese Translation. Similarly, there are also other types of BLDs apart from learner's dictionaries, such as An English-Chinese Dictionary of Business Management, A Dictionary of Everyday English Metaphors, and A Bilingual Chinese-English Dictionary of English Synonyms. Compared with those adapted from monolingual learner's dictionaries abroad, the BLDs compiled by Chinese natives are far less known or used.

A random search of any major bookstore in China may give one the impression that BLDs have dominated the dictionary market. Indeed, many surveys on dictionary use by Chinese EFL students have indicated that, among various paper dictionaries, the BLD is by far the most popular and used most frequently. Over a decade ago, Yu (1999) found that both English and nonEnglish majors in his sample of population preferred the use of BLDs, such as Oxford Advanced Learner's English-Chinese Dictionary (OALECD) and Longman English-Chinese Dictionary of Contemporary English (LECDCE). The BLD ownership rate by English majors reached $86.0 \%$. Findings by Lang and Li (2003), as well as Kan and Wang (2003), supported that BLDs were most preferred by EFL students, with OALECD taking the lead, followed by LECDCE. In Shi and Pan (2005), 78.2\% of non-English majors owned OALECD and in Shi and Chen (2007), the ownership rate of BLDs by English majors reached $87.5 \%$. The popularity of BLDs with EFL learners was further corroborated by Jiang (2007) and $\mathrm{Li}$ (2009). In Chen's (2007) large-scale survey, the BLD was found again to be owned by more than half of the respondents and perceived as the most useful type of dictionary for EFL learning. The BLD ownership rate rose to $76.5 \%$, according to Chen's more recent study (2011a). Actually, at the university where the author works as an EFL teacher, each English major owns an OALECD.

The BLD also enjoys huge popularity among tertiary-level students in Hong Kong. Fan (2000) reported that a majority of over 1000 respondents often used BLDs and also thought highly of them. Chi (2003) showed that OALECD was most popular with her subjects and also used most frequently. As confirmed by Thumb (2004), OALECD and LECDCE were particularly well received by the Chinese learners of English in Hong Kong. In a more recent study, Chan (2011) 
indicated that $79 \%$ of the ESL (English as a Second Language) respondents used BLDs either exclusively or together with monolinguals.

Unlike the overwhelming popularity of BLDs over bilinguals and monolinguals in the paper medium, the situation with electronic BLDs is not so clearcut. Theoretically speaking, all types of paper dictionaries can be converted into electronic forms, be they web-based (e.g. online dictionaries), PC-based (e.g. computer desktop dictionaries), or chip-based (e.g. pocket e-dictionaries). However, owing to the scanty research in the use of electronic dictionaries (except for pocket e-dictionaries) in China, one cannot claim with complete assurance that electronic BLDs are more popular than electronic bilinguals or monolinguals, although dictionary users show a clear preference for electronic dictionaries over paper ones.

As far as pocket e-dictionaries are concerned, despite the differences in the configuration of installed dictionaries, almost all major brands on the market such as CASIO (卡西欧), Wenquxing (文曲星), Nuoyazhou (诺亚舟), Kuaiyitong (快译通), Kuaiyidian（快易典）， Mingren (名人），and Bubugao (步步高) contain various types of dictionaries, including BLDs, bilinguals and monolinguals. An overwhelming majority of BLDs installed in pocket e-dictionaries are adapted from the "Big Five", and the more expensive the pocket dictionary is, the better version of BLD it includes. Nevertheless, contrary to the case with paper BLDs, there is little evidence to support that students prefer to use electronic BLDs over other types of dictionaries installed in their pocket dictionaries. As for other forms of electronic dictionaries such as online dictionaries, computer desktop dictionaries and cell phone dictionaries, the situation is even more unclear as there are hardly any surveys in this regard.

\section{BLDs: dictionary typology}

It is notoriously hard to provide an ideal framework for dictionary classification, as it can be based on various criteria. Considering the marginal status of the BLD in the western lexicographical circle, it is not surprising that little effort has ever been made to classify this type of dictionary except for a couple of studies, i.e., James (1994) and Marello (1998).

\subsection{James' typology of BLDs}

Based on an extensive historical survey of BLDs for a variety of languages, James distinguishes three subtypes of the genre (James 1994, 2000, Hartmann 2001: 77, adapted for the EFL context by the author):

- Learner's dictionary: a monolingual learner's dictionary in the user's target language, with glosses in the user's first language to assist decoding tasks, e.g. an English-English-Chinese dictionary for Chinese learners of English. 
- Teaching dictionary: a monolingual dictionary intended for native speakers, adapted for learners by the addition of glosses in their first language (and sometimes the deletion of all or part of the original definitions) to help decoding, e.g. an English (-English) dictionary with Chinese glosses, for Chinese learners of English.

- Learning dictionary: a monolingual dictionary intended for native speakers, with glosses in the user's target language(s) to assist encoding, e.g. a Chinese-Chinese dictionary with English glosses, for Chinese learners of English.

Within the "learner's dictionary", James further identified two subtypes: one is "monolingual adapted", i.e. the bilingualization of an already existing dictionary, the other "originally bilingual", i.e. definitions and equivalents are written by the same writer(s) (which has been the norm in the Indian sub-continent). The "teaching dictionary" may include dictionaries whose original forms are retained but with the addition of L2 glosses, and dictionaries whose original definitions are simplified. With regard to the "learning dictionary", there are also two subtypes: one for native speakers and the other for learners of the second language (James 2000).

Despite his ingenious ideas, James only provides a crude typology for BLDs. The names of the BLD types seem a little confusing and the categorization of BLD subtypes is based on random criteria. As can be seen above, the "learner's dictionary" is further classified according to dictionary compilers; the categorization of the "teaching dictionary" is based on dictionary contents, while the "learning dictionary" is further grouped from the perspective of target dictionary users. It can be argued that these three subtypes can also be categorized according to other criteria. Furthermore, there are other BLDs which may not fit in this framework.

\subsection{Marello's categorization of BLDs intended for learners}

Marello (1998) explored the bilingualized learner's dictionary with a special reference to A. S. Hornby's works. By examining closely a dozen BLDs adapted from Hornby's dictionary family into various languages, Marello clearly demonstrates that BLDs can differ in their degree of bilingualization as a consequence of using L1 or L2 in a given part of the dictionary article according to the purposes of users and their L2 proficiency levels. Some BLDs were found to have the minimum amount of bilingualization with simple and short glosses added only to entry definitions; some preserve all original information and translate it into L1, thus gaining the maximum amount of bilingualization, and others delete, add or substitute part of entry information and provide translation for headwords and/or examples.

Indeed, as argued by Cowie (1999: 195), "If progress is to be made towards 
a precise categorization of bilingualized dictionaries, it is essential to recognize the sources from which they come, as well as the modifications made to the parent works and the purposes these are intended to serve." Marello (1998) presents an analytical framework for the BLDs based on Hornby's works by examining their source and modifications, thus broadening our understanding about BLDs, yet she focuses on only one of the various subtypes of BLDs, i.e. the learner's dictionary. There are also other genres which have been bilingualized, such as pictorial dictionaries and thesauruses. The dictionary examples listed in Section 2.2 also show the wide variety of BLDs available on the Chinese EFL dictionary market. Therefore, the classification of BLDs should be explored from a broader perspective.

\subsection{Some tentative approaches to classifying BLDs}

It is true that the development of BLDs parallels those in monolingual and bilingual lexicography (Hartmann 1993). There is now a widening range and scope of monolingual and bilingual dictionaries, so is the case with BLDs. Theoretically speaking, a majority of monolinguals and bilinguals can be bilingualized with only a few exceptions such as pronouncing dictionaries, dictionaries of synonyms/antonyms and dictionaries of etymology. Therefore, BLDs can be classified according to the same criteria as those applied to monolinguals or bilinguals. Nevertheless, as a type of dictionary with a hybrid nature, the categorization of BLDs can also be based on its own unique criteria. The author proposes the following tentative approaches to classifying BLDs.

\section{- $\quad$ From the dictionary proper}

BLDs can be distinguished according to the dictionary proper. Like monolinguals and bilinguals, the classification of BLDs can be based on various criteria. For example, we can distinguish BLDs by purpose (descriptive vs. prescriptive, active vs. passive, general-purpose vs. specialized), by function (encoding vs. decoding, academic vs. pedagogical), by predominance of information categories provided (linguistic vs. encyclopedic), by format (alphabetical vs. morphological vs. thematic), by medium (print vs. electronic), by size (from unabridged to gem), and by user type (advanced-level vs. medium-level vs. elementary-level, adult dictionary vs. children's dictionary) (Hartmann and James 2000: 147, Zhang and Yong 2007: 97).

\section{- From the dictionary compiler}

From the perspective of dictionary compilers, there are two categories of BLDs. One is the translated BLD which is based on monolingual dictionaries, like the BLDs adapted from the "Big Five", in which the L1 and L2 information is provided by compilers from different language back- 
grounds. The other is the independently compiled BLD in which the L1 and L2 information is given by the same compiler. Within the former category, the BLD can be further divided according to the degree of bilingualization. Some BLDs are the products of full bilingualization in which (almost) all entry information is translated into another language, like OALECD and LECDCE, while others are semi-bilingual with only part of entry information translated, like those popular in Israel.

- From the style of language presentation

Based on the style of language presentation, there are two kinds of BLDs. One is the traditional BLD characterized by a juxtaposition or simultaneous presentation of L1 and L2 information. For example, the English definition is followed immediately by the Chinese translation, as in most of the English-Chinese BLDs in China. The other type of BLDs, however, separates the L1 and L2 information as an effort to increase the exposure to L2. For example, most BLDs in Israel provide a brief gloss for the L2 definition which is placed after an untranslated dictionary example instead of right after the L2 definition. The print deferred BLD introduced by Pujol et al (2006) is another case in point. Such a BLD is divided into a L2-L2 monolingual part and a L2-L1 bilingual part that are interconnected by means of page numbers. A couple of English-Chinese BLDs are also characterized by a separation of L1 and L2 information, yet in a different way, i.e. to divide each dictionary page into two columns, the left-column being the L2 information and the right-column the corresponding information in the L1.

James (2000: 143-144) observes:

That, as yet, we have only an imperfect taxonomy of the genre of bilingualized dictionaries is perhaps a result of the stigma still attaching in some quarters to any but monolingual target-language dictionaries for learners, and the notion that bilingualized dictionaries are somewhat of a half-way house, a pandering to learners who have not acquired adequate study skills to master a monolingual dictionary.

Undoubtedly, there is still a long way to go before an ideal taxonomy of BLDs is reached, especially with the rise and popularity of various electronic dictionaries which have made a real impact on the dictionary scene.

\section{BLDs: dictionary criticism}

\subsection{Perceived strengths and weaknesses of BLDs}

The trend towards BLDs is in line with the double criticism that, on the one 
hand, monolingual learner's dictionaries are too much like native-speaker dictionaries and, on the other hand, straightforward bilingual dictionaries are too far removed from the target language (Hartmann 1991: 79, cited in Fan 2000: 125). By including entry information in both L1 and L2, the BLD is assumed to combine the authenticity and reliability of the monolingual dictionary and the accessibility of native-language equivalents/translations of the traditional bilingual dictionary (Tseng 2005). The unique combination of L2 + L1 information can thus both assist learners with difficulty in understanding the L2 definition and help prevent the undifferentiated equation between L2 and L1 words. In particular, L1 translation in BLD entries can supplement the L2 definition, correct a misconception about it, reinforce user's understanding of the L2 headword, and meet their psychological need to know the equivalent in L1 Furthermore, the BLD entry formula helps prevent the misconception about one-to-one equivalence between L1 and L2 words (Nakamoto 1995, Thumb 2004: 20-21). In brief, the strength of BLDs "derives from their synergy: they bring together the advantages of two types of dictionary that for a long time have been regarded as irreconcilable and, hence, have been used (and sold) separately" (Pujol et al. 2006: 200).

Despite its perceived advantages, the BLD has also attracted some criticism. It is considered as "insufficient with regard to the standards which ought to be set for a true bilingual learner's dictionary" (Zöfgen 1991: 2889), yet this comment is refuted as "off the point" by Nakamoto (1995) as the BLD he discussed (the case of the semi-bilingual) is basically a monolingual work. Due to its unidirectionality, the BLD is of "limited usefulness" except for decoding (Hartmann 1994, Cowie 1999: 195). However, as revealed by a recent large scale survey (Chen in preparation), apart from reading, BLDs are also often referred to for translation, and collocational information in BLD entries is frequently used for encoding purposes. Another perceived shortcoming of the BLD is connected with the neglect or underuse of L2 information on the part of dictionary users (Pujol et al. 2006), as some evidence showed that learners prefer to read L1 rather than both languages (Fan 2000, Laufer and Kimmel 1997, Thumb 2004). Actually, this so-called drawback is more concerned with dictionary users' preference than with the inherent problem of the BLD itself. Besides, some studies (Chen 2011b, in preparation) indicate that most Chinese EFL learners prefer to use both languages in BLD entries.

According to Tseng (2005), the "irreversible inherent shortcoming" of the BLD is a lag behind its monolingual parent work in terms of the currency of the contents. Considering the time needed for a bilingualization project and the active nature of the lexicon, we cannot but agree with Tseng's opinion. Still, this point is irrelevant when it comes to the independently compiled BLDs.

It is argued that during bilingualization intercultural problems are bound to arise, especially when most BLD translators come from different linguistic and cultural backgrounds (Yao, 2004). This pessimism about the role of the translated BLD in intercultural communication was echoed by Zhang (2010) 
who held a critical attitude towards such BLDs, asserting that they are based on the cognitive thinking of Western people, split the language system into distinct parts and are organized by a grammar-centered approach. Indeed, the source dictionary of the translated BLD is usually designed without differentiating country-specific learners and thus may fail to meet the specific needs of users from different linguistic and cultural backgrounds.

Apart from the above criticism, another point about the BLD should also be mentioned, i.e. its bulkiness. Since this type of dictionary contains both L2 and L1 information, it is usually big and heavy, which induces inconvenience in use and extra cost. Of course, this is not a problem with electronic BLDs.

It should be noted that, whatever the advantages or disadvantages claimed, they are mostly based on pedagogical intuition or theoretical speculation rather than empirical evidence. More empirical information is needed to argue for or against the use of BLDs. This is the very reason to call for more systematic and in-depth research on the use and usefulness of this type of dictionary.

\subsection{BLDs and pedagogical lexicography}

Teachers, lexicographers, linguists and users have much to gain from an increased awareness of the role of dictionaries in the language-learning process (Hartmann 1993). The growing market of monolingual learner's dictionaries has attracted extensive interest in pedagogical lexicography. However, within this flourishing field of research, the BLD seems to have drawn much less attention than it deserves. A few remarks about the BLD in language learning have been made, but only in passing (e.g. Atkins 1985, Thompson 1987, Wingate 2002, Lew 2004). Hartmann $(1993,1994)$ was one of the first to examine the BLD both theoretically and empirically, advocating that one of the priorities of pedagogical lexicography must be to critically evaluate the development of BLDs. In reviewing the types of user-related research, Cowie (1999: 177), based on the four points of focus summarized by Hartmann (1987), adds another two types of enquiry:

- Assessment of the special merits of the so-called bilingualized dictionary as compared with the standard monolingual or bilingual learner's dictionary.

- Consideration of which types of dictionary - monolingual, bilingual or bilingualized - need to be used at various phases of the learning process and for what purposes.

In fact, the evaluation of the BLD did not begin until the end of the last century, Overall, the BLD seems to have been placed in a position between monolinguals and bilinguals, playing a gap-bridging role. Cowie (1999: 195) asserts that the BLD "cannot supplant the monolingual learner's dictionary", but it can 
"serve as a bridge between a standard bilingual and a fully-fledged monolingual work". In her investigation into the use of dictionaries for reading comprehension, Wingate (2002: 230) made a passing comment that the BLD might be the ideal solution for the intermediate learners, since they could "facilitate the transition from bilingual to monolingual dictionaries". Lew (2004) found that those entries with two ways of meaning provision had a confusing effect on learners at the lower levels, probably owing to their overcrowded information. However, Laufer and Hadar (1997: 195) argued with empirical evidence that a good BLD is suitable for all types of learners: unskilled dictionary users may rely mostly on the bilingual information. With progress in these skills, the monolingual information will gain relevance and importance.

In China, there is a body of dictionary reviews concerning particular BLD titles, yet they seem to suffer from inconsistent criteria for critical evaluation. As for the role of the BLD in EFL pedagogy, no consensus has ever been reached. Chen (2006) gives a detailed explanation of the rationale behind the BLD and argues that it can cater to the cognition of EFL learners and play a positive role in EFL learning. However, according to Zhang (2010), the BLD cannot meet the needs of Chinese EFL learners, because its source dictionary is designed without differentiating specific needs of learners in different countries. Yao (2004) also advocates a reevaluation of the role that mother tongue and bilingual/bilingualized dictionaries play in EFL learning.

Actually, the BLD assessment would never be complete, valid or convincing without the support of empirical evidence. Theoretical exploration of BLDs should go hand in hand with investigations into the use and usefulness of such dictionaries in language pedagogy.

\section{BLDs: dictionary use}

On the whole, published research on BLD use is minimal, with only a handful of studies which investigated one or more of the following aspects of dictionary use:

\section{1 Perceptions of BLDs and patterns of use}

One of the earliest BLD use studies was reported by Hartmann (1994) who found that users appreciate the juxtaposition of target-language definitions and mother-tongue translations. The BLD can serve a useful function for decoding and provide a bridge between the traditional bilingual dictionaries and monolingual dictionaries aimed at more advanced learners. Though limited in the scope of research and methodology, Hartmann did succeed in sparking more interest in BLD use research.

Some research findings indicate that users tend to read either L1 or L2 rather than both in BLD entries. In her investigation into the use and evaluation 
of various BLD information by Hong Kong tertiary-level students, Fan (2000) discovered that L1 equivalents were used significantly more often than L2 definitions though the latter were perceived as more useful than the former. Thumb (2004) confirmed that more students preferred to read L1 rather than L2 or both when using BLD entries. Such a general preference was corroborated by Laufer and Kimmel (1997) who reported that Israeli students tended to use the L1 or the L2 significantly more often than L1 + L2. However, Chen (2011b) revealed a different language preference: most students in her study liked to read both L1 and L2 instead of one of the two languages. Such finding is supported by the author's most recent research (Chen in preparation) which investigated BLD users' lookup behavior in CALL context. The discrepancies between Chen's findings and those of other researchers may be attributed to the subjects involved: Chen targeted at English majors who owned and often used BLDs while students in the other studies were at a lower level of English proficiency and may not be accustomed to BLD use.

Due to its distinctive feature of meaning presentation, the BLD is found to cater to a variety of lookup possibilities, individual preferences and proficiencies. Thumb (2004: 108) manifested that the BLD is "highly usable and useful because of its compatibility with the language needs of learners". Users displayed various individualized lookup patterns: some read only L1 or L2 for all lookups, some alternated between the two languages, some referred persistently to L1 + L2 while a few had a mixed use of L1, L2 and L1 + L2. Laufer and Kimmel (1997) identified five patterns of BLD use while in Chen (2011b), two more patterns turned up. Higher-level students tended to make better use of BLD features than lower-level ones (Fan 2000, Chen 2011b).

It seems that BLD users make only limited use of the dictionary as they tend to ignore the information concerning the habitual and idiomatic use of L2 words (Fan 2000). Among the various entry components, students consulted the context meaning of words most frequently, yet they seldom looked up information related to collocations, pronunciation, frequency, and appropriateness of words, and except for collocation, the above-mentioned information was also considered least useful. Such ignorance of these aspects of word knowledge is a "cause for concern" (Fan 2000: 134).

Efforts have also been made to explore the cognitive strategies during dictionary consultation. Thumb (2004) uncovered seven strategies of BLD use, i.e. ignoring, assuming, minimizing, checking, paraphrasing, stretching, and maximizing. The same strategy used by two different learners could produce different outcomes while the same strategy used to look up different words could produce the same outcome (Thumb 2004: 109). Despite the problems with the methodological issues (Bogaards 2005), Thumb did provide an interesting description of the highly complex and individual lookup strategies that also applied to the use of monolingual and bilingual dictionaries.

A couple of studies provided more detailed information about general BLD use and BLD perceptions. Chen (2011a) is the first one to focus exclusively 
on BLD use in the Chinese EFL context, looking into several aspects of dictionary use, such as the degree of popularity of BLDs, the reference needs for BLDs, the reference skills of BLD users, the perceptions and evaluations of BLDs, and the needs of BLD users. Based on Chen (2011a), in Chen (in preparation), the scope of research was widened by covering the differences between paper BLDs and electronic BLDs in patterns of use and dictionary evaluation. Chan (2011) looked into the preferences and practices of Cantonese ESL learners which are mainly associated with BLDs and monolingual dictionaries. The study included investigations into the usual pattern of using a dictionary, the reasons for preferring BLDs over monolingual dictionaries or vice versa, and learners' perception of the disadvantages of both dictionary types.

\section{2 Dictionary effectiveness}

A few studies compared the dictionary effectiveness between the BLD and other dictionary types for certain linguistic tasks. Laufer and Melamed (1994), later published as Laufer and Hadar (1997), is the earliest research into BLD use. They found that the BLD was substantially better than the bilingual and monolingual dictionaries for vocabulary comprehension and also significantly better than the monolingual dictionary for vocabulary production. Except for unskilled users, all levels of dictionary users under the BLD condition achieved the best results of task completion. Chen (2011b) yielded similar findings: the BLD was significantly better than the bilingual and the monolingual in terms of its overall effects on the comprehension and production of new words. In addition, BLD use also brought favorable results of vocabulary retention. The overall advantages of the BLD were confirmed again in the author's latest study (Chen in preparation) which involved more vocabulary tasks and retention tests. Furthermore, some problems with BLD use were also identified and discussed.

The merits of the BLD over other dictionary types was also reported by Raudaskoski (2002) who found that those using the BLD made more improvement in their translation performance than those using the bilingual. Unfortunately, the degree of difference in improvement between the two groups is not reported, and no attempt at statistical evaluation is claimed (Lew 2004: 30). The study by Zarei (2010) presented a more complicated picture. He noted that for elementary- and intermediate-level students, the use of the BLD obtained the highest post test scores for both comprehension and production tasks, yet for advanced students, the BLD ranked second in terms of effectiveness for comprehension and third for production.

These studies have cast some light on the effectiveness of different dictionary types in language learning. However, there is a methodological problem undermining the credibility of test results of this kind, i.e. the unbalanced choice of dictionary titles (Marello 1998, Cowie 1999, Tono 2000, Lew 2004). The low degree of comparability between dictionaries involved or the lack of con- 
trol of lexicographic presentation that characterizes most of the studies (e.g. Laufer and Hadar 1997, Raudaskoski 2002, Zarei 2010) might make it premature to generalize the results with specific dictionary titles to general dictionary types. Bearing this methodological issue in mind, Lew (2004) designed some balanced entries for different dictionary types and compared their effectiveness for receptive tasks. The findings indicated that BLDs were significantly more effective than the monolinguals, yet, with two ways of meaning provision, such dictionaries may be too crowded and thus confusing to learners at the lower levels. The advantage of the BLD over the monolingual dictionary was supported by $\mathrm{Hu}$ (2009) who, in an investigation into the effects of different tasks on incidental vocabulary learning of Chinese EFL learners, reported that the BLD dwarfed the monolingual one on vocabulary retention tests. Both Lew and $\mathrm{Hu}$ used minidictionaries specially written for experimental studies. Although the degree of comparability between dictionaries is guaranteed, it can be argued that there may be difference in dictionary use between real-life and artificial conditions.

Laufer and Levitzky-Aviad (2006) compared an experimental L1-L2-L2 dictionary (called bilingual plus), both in paper and computerized forms, with a BLD and a traditional bilingual dictionary for L2 production. The results pointed to a clear advantage of such a dictionary. The authors (Laufer and Levitzky-Aviad 2006: 152) attributed its effectiveness to "the combination of the bilingual and monolingual information which most learners used". It should be mentioned here, though, that the BLD involved in their study was a unidirectional L2-L1 one and was obviously placed at a disadvantage for an L1-L2 translation task.

There are also a couple of studies comparing the effects of BLDs in different media. Chen (2010) revealed that there was no significant difference in dictionary effectiveness between a paper BLD and BLDs stored in pocket e-dictionaries for the comprehension, production and retention of new words. The finding was corroborated by Chen (2012) which involved the use of a computer desktop BLD and its printouts. It seems, as far as BLDs are concerned, outcomes of vocabulary learning are not dependent on the form of dictionary used.

\subsection{Language-oriented lookup behavior in CALL context ${ }^{3}$}

Several researchers used electronic dictionaries together with built in log files to investigate dictionary users' language-oriented lookup behavior and its effect on vocabulary comprehension, production and retention. With a specially designed CALL dictionary program which incorporated L2 explanation, L1 translation, sound, root and "extra" information, Laufer and Hill (2000) discovered that Hong Kong learners preferred to look up the L2 definition rather than L1 translation while Israeli learners had a reverse preference. Yet, despite such difference between the two learner groups, the use of L1 together with L2 led to good retention. The beneficial effects of L1 + L2 lookup, as noted by 
Laufer and Hill (2000: 17), may lie in the richness of semantic encoding, or the prolonged attention that multiple items of information require, or both. In a replication study, Lew and Doroszewska (2009) reported that it was the L1 equivalent, alone or in combination with the L2 definition that was the best predictor of retention as well as being the most popular target of consultation. They (Lew and Doroszewska 2009: 253) also discovered that retention rates were not affected by the sheer amount of dictionary activity, thus leading to the conclusion that it is the quality rather than the quantity of lookups that makes a real difference.

To the author's knowledge, Liu (2007), later published as Chen and Liu (2008), and Chen (in preparation) are the only studies that adopted the CALL methodology to examine dictionary users' lookup behavior in the Chinese EFL context. Liu (2007) incorporated various pieces of dictionary information into a CALL program used for reading comprehension and found that the L1+L2 lookup pattern seemed to be very effective for word retention, a finding similar to Laufer and Hill's (2000). Different from Lew and Doroszewska (2009), Liu identified a significant correlation between the number of word clicks and vocabulary retention scores. Although the study failed to present and discuss the results in a concise and coherent manner, it seems to take the lead in terms of the methodology of dictionary use research in China.

Chen (in preparation) also used log files to record users' lookup behavior and explore its impact on vocabulary learning under CALL context. A general preference for a combined use of L2 definition and L1 translation was observed. Users demonstrated various lookup patterns, among which, the L2 + L1 pattern proved to be most conducive to incidental vocabulary learning. Similar to Lew and Doroszewska's finding (2009), there was no strong correlation between the amount of dictionary activity and the outcomes of vocabulary learning. Furthermore, students at different levels of vocabulary proficiency did not differ significantly in terms of dictionary click behavior.

\section{Conclusion}

As a type of dictionary with unique features, the BLD is particularly wellreceived by Chinese EFL learners. Considering its popularity in EFL learning, the research into this type of dictionary is of direct relevance to language pedagogy, dictionary use instruction and lexicographic practices. The investigation into the patterns and strategies of BLD use can provide useful insights and reference for language teaching, particularly for vocabulary pedagogy. By learning about users' needs and reference skills and identifying the problems with BLD use, we can enhance students' awareness of the role of dictionaries in language learning process and improve their dictionary use competence. Furthermore, besides a fundamental knowledge of the history and features of the BLD, the elicited information about users' needs and expectations also has significant bearings on lexicographic practices. This article provides an overview 
of the BLD from several branches of dictionary research, including dictionary history, dictionary typology, dictionary criticism and dictionary use. It is hoped that such a review would attract more attention to the BLD from researchers all over the world.

Compared with its large scale of use, the research on the BLD is far from sufficient. There remain many opportunities for further inquiry. As far as dictionary use is concerned, more research should be carried out to investigate the cognitive strategies of BLD use, especially during the lookup process of electronic BLDs. It would be illuminating to examine the effectiveness of BLDs for other language activities besides vocabulary learning, such as text translation and passage writing. It would also be interesting to examine the relation between dictionary use strategy and other vocabulary learning strategies. In addition, more rigorous research design should be adopted to identify specific problems with BLD use. Aside from questionnaires, surveys, interviews, tests and experiments, other methodologies such as observation, self-account, thinkaloud protocols, video taping, and server logging etc. could also be usefully exploited.

From a lexicographic perspective, a lot of theoretical and practical issues remain to be solved. Systematic lexicographic principles should be drawn to guide the production or bilingualization of BLDs. How to independently produce high quality country-specific BLDs in response to the language cognition and special needs of BLD users is a huge project that requires effort and collaboration of scholars from different lines. As to the translated BLDs, more research could be done with regard to translation principles and translation skills of headwords and examples, as such issues are the key to BLD bilingualization. It is also worthwhile to explore how to improve the encoding function of BLDs so as to enhance their usefulness for language learning.

As BLDs are used extensively at Chinese colleges and universities, it is also necessary to conduct more studies that are directed at the BLD use instruction. It is of pedagogical significance to find out more about problems and pitfalls of BLD use and provide systematic guidance on the proper use of this type of dictionary. In this regard, more remains to be done. 


\section{Notes}

1. See the following excerpts from the most popular BLDs at the Chinese EFL dictionary market.

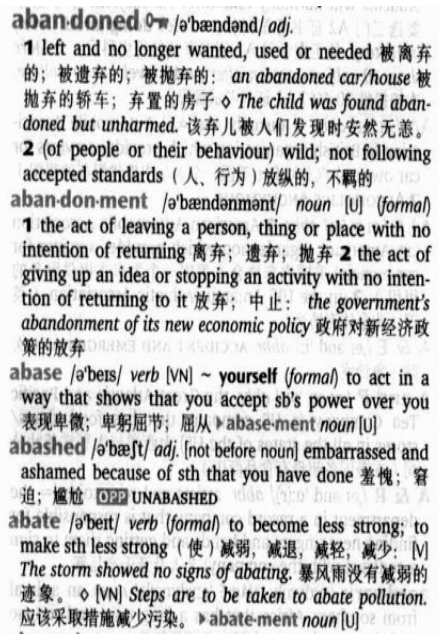

Figure 1: An excerpt from Oxford Advanced Learner's English-Chinese Dictionary (7th edition)

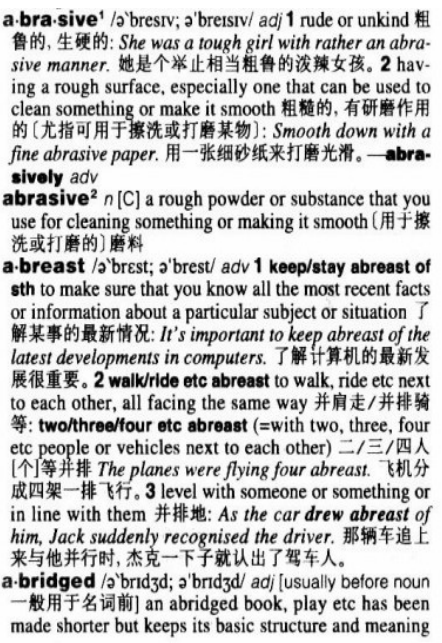

Figure 2: An excerpt from Longman Dictionary of Contemporary English (English-Chinese, 4th edition)

2. Semi-bilingual dictionaries are popular in the Middle East and Europe while in China there are only a couple of such dictionaries available, i.e. Password English-Chinese Semi-bilingual Dictionary (《半双解英汉词典》) and Bookman English Dictionary for Speakers of Chinese (《书林易解英语词典》). The following is an example excerpt.

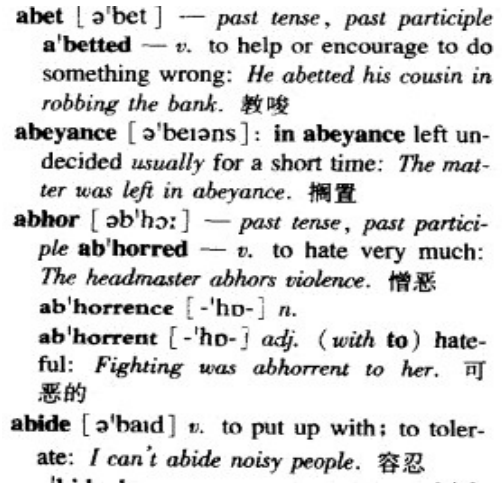

Figure 3: An excerpt from Password English-Chinese Semi-bilingual Dictionary 
3. Strictly speaking, most of the studies reviewed in this section did not target at BLD use, yet, since these studies all involved language-oriented lookup preference of dictionary users, they are assumed to be relevant to the review.

\section{References}

Atkins, B.T.S. 1985. Monolingual and Bilingual Learners' Dictionaries: A Comparison. Ilson, R. (Ed.). 1985. Dictionaries, Lexicography, and Language Learning: 15-24. Oxford: Pergamon Press.

Bogaards, P. 2005. Review of Jenny Thumb. Dictionary Look-up Strategies and the Bilingualised Learner's Dictionary. International Journal of Lexicography 18(2): 272-274.

Chan, A. 2011. Bilingualised or Monolingual Dictionaries? Preferences and Practices of Advanced ESL Learners in Hong Kong. Language, Culture and Curriculum 24(1): 1-21.

Chen, W. 2006. Semi-bilingual Dictionary and Foreign Language Learning - A Case Study of Semi-bilingual Dictionaries. Foreign Languages in China 3: 62-66.

Chen, Yuzhen. 2007. A Survey of English Dictionary Use by English Majors in Chinese Universities. Lexicographical Studies 2: 120-130.

Chen, Yuzhen. 2010. Dictionary Use and EFL Learning: A Contrastive Study of Pocket Electronic Dictionaries and Paper Dictionaries. International Journal of Lexicography 23(3): 275-306.

Chen, Yuzhen. 2011a. A Questionnaire Survey and Experimental Study of English-Chinese Bilingualized Dictionaries. Lexicographical Studies 2: 141-158.

Chen, Yuzhen. 2011b. Studies on Bilingualized Dictionaries: The User Perspective. International Journal of Lexicography 24(2): 161-197.

Chen, Yuzhen. 2012. Dictionary Use and Vocabulary Learning in the Context of Reading. International Journal of Lexicography 25(2): 216-247.

Chen, Yuzhen. In preparation. Dictionary Use and EFL Vocabulary Learning: An Empirical Research of English Majors' Use of Bilingualized Dictionaries in China. Ph.D. Thesis, Xiamen University.

Chen, Y.P. and O. Liu. 2008. A Study of Annotation Information L2 Learners Select and Factors Affecting Word Retention on CALL Model. Journal of Architectural Education in Institutions of Higher Learning 17(4): 134-138.

Chi, A. 2003. An Empirical Study of the Efficacy of Integrating the Teaching of Dictionary Use into a Tertiary English Curriculum in Hong Kong. Hong Kong: Hong Kong University of Science and Technology.

Cowie, A.P. 1999. English Dictionaries for Foreign Learners: A History. Oxford: Clarendon Press.

Fan, M.Y. 2000. The Dictionary Look-up Behavior of Hong Kong Students: A Large-scale Survey. Educational Journal 28(1): 123-138.

Hartmann, R.R.K. 1987. Four Perspectives on Dictionary Use: A Critical Review of Research Methods. Cowie, A.P. (Ed.). 1987. The Dictionary and the Language Learner: 11-28. Tübingen: Max Niemeyer.

Hartmann, R.R.K. 1991. What's the Use of Learners' Dictionaries? A lecture given at the City Polytechnic of Hong Kong.

Hartmann, R.R.K. 1993. Recent Trends in Pedagogical Lexicography: the Case of the 'Bilingualised' Learner's Dictionary. Crochetiere, A. et al. (Eds.). 1993. Proceedings of the15th International Congress of Linguistics Vol.2: 159-162. Quebec: Laval University Press. 
Hartmann, R.R.K. 1994. Bilingualised Versions of Learners' Dictionaries. Fremdsprachen Lehren und Lernen 23: 206-220.

Hartmann, R.R.K. 2001. Teaching and Researching Lexicography. Harlow: Pearson Education.

Hartmann, R.R.K. and Gregory James. 2000. Dictionary of Lexicography. Beijing: Foreign Language Teaching and Research Press.

Hu, M.Y. 2009. L2 Incidental Vocabulary Learning and Retention: Efficacy of Dictionary-assisted Written Exercises. M.A.. Dissertation, Suzhou University.

James, G. 1994. Towards a Typology of Bilingualized Dictionaries. James, G. (Ed.). 1994. Meeting Points in Language Studies: A Festschrift for Ma Tailai. Working Papers: 184-196. Hong Kong: Hong Kong University of Science and Technology Language Center.

James, G. 2000. Bilingualisation as a Genre. James, G. 2000. Colporul: A History of Tamil Dictionaries: 450-458. Chennai: Cre-A.. Reprinted in Hartmann, R.R.K. (Ed.). 2003. Lexicography: Critical Concepts .Vol. 3: 135-146. London: Routledge.

Jiang, Y.J. 2007. An Inspiration of a Questionnaire on English Majors' Dictionary Use. Journal of Guangdong Polytechnic Normal University 4: 107-110.

Kan, H.W. and Y. Wang. 2003. Survey of Dictionary Use by English Majors in Shanghai University. Zeng, D.J. (Ed.). 2003. Bilingual Dictionary Studies: 391-399. Shanghai: Shanghai Foreign Language Education Press.

Lang, J. and J. Li. 2003. A Survey of English Dictionary Use. Journal of Beijing International Studies University 6: 54-60.

Laufer, B. and L. Hadar. 1997. Assessing the Effectiveness of Monolingual, Bilingual, and "Bilingualised" Dictionaries in the Comprehension and Production of New Words. The Modern Language Journal 81(2): 189-196.

Laufer, B. and M. Hill. 2000. What Lexical Information do L2 Learners Select in a CALL Dictionary and How Does it Affect Word Retention? Language Learning and Technology 3(2): 58-76.

Laufer, B. and M. Kimmel. 1997. Bilingualized Dictionaries: How Learners Really Use Them. System 25(3): 361-369.

Laufer, B. and T. Levitzky-Aviad. 2006. Examining the Effectiveness of "Bilingual Dictionary Plus" - A Dictionary for Production in a Foreign Language. International Journal of Lexicography 19(2): 135-155.

Laufer, B. and L. Melamed. 1994. Monolingual, Bilingual and "Bilingualised" Dictionaries: Which are More Effective, for What and for Whom? Martin, W. et al. (Eds.). 1994. EURALEX 1994 Proceedings, Papers submitted to the 6th EURALEX International Congress on Lexicography in Amsterdam, The Netherlands: 565-576. Amsterdam: Vrije Universiteit.

Lew, R. 2004. Which Dictionary for Whom? Receptive Use of Bilingual, Monolingual and Semi-bilingual Dictionaries by Polish Learners of English. Poznań: Motivex.

Lew, R. and J. Doroszewska. 2009. Electronic Dictionary Entries with Animated Pictures: Lookup Preferences and Word Retention. International Journal of Lexicography 22(3): 239-257.

Li, Z. 2009. On the English Majors' Use of Dictionaries. Journal of Guangdong University of Foreign Studies 6: 97-100.

Liu, O. 2007. Research on the Relation between Lexical Information L2 Learners Select in CALL Dictionary and Word Retention. M.A.. Dissertation, Chongqing University.

Marello, C. 1998. Hornby's Bilingualized Dictionaries. International Journal of Lexicography 11(4): 292-314. 
Nakamoto, K. 1995. Monolingual or Bilingual, that is not the Question: The Bilingualized Dictionary. Available at http:/ / kdictionaries.com/newsletter/ kdn2-2.html4.

Osselton, N.E. 1995. Chosen Words: Past and Present Problems for Dictionary Makers. Exeter: University of Exeter Press.

Pujol, D, M., M. Corrius and J. Masnou. 2006. Print Deferred Bilingualized Dictionaries and Their Implications for Effective Language: A New Approach to Pedagogical Lexicography. International Journal of Lexicography 19(2): 197-215.

Raudaskoski, S. 2002. Translation, the Key or the Equivalent? Kernerman Dictionary News 10: 2-3.

Shi, B. and P. Pan. 2005. Analysis of a Survey on English Learning Dictionary Using.. Journal of Shanxi Coal-Mining Administrators College 3: 78-79.

Shi, G.S. and G.H. Chen. 2007. Survey of Dictionary Use by English Majors. Foreign Language Research 1: 66-69.

Thompson, G. 1987. Using Bilingual Dictionaries. ELT Journal 41(4): 282-286.

Thumb, J. 2004. Dictionary Look-up Strategies and the Bilingualised Learner's Dictionary: A Think-aloud Study. Lexicographica. Series Maior 117. Tübingen: Max Niemeyer.

Tono, Y. 2000. On the Effects of Different Types of Electronic Dictionary Interfaces on L2 Learners' Reference Behavior in Productive/Receptive Tasks. Heid, U., S. Evert, E. Lehmann and C. Rohrer (Eds.). 2000. Proceedings of the Ninth EURALEX International Congress, EURALEX 2000, Stuttgart, Germany, August 8th-12th, 2000: 855-861. Stuttgart: Institut für Maschinelle Sprachverarbeitung, Universität Stuttgart.

Tseng, Hugo T.Y. 2005. Reverse Indexing and Customization - Future Trends in Bilingualized Dictionaries. Paper presented at Fourth ASIALEX Biennial Conference, Singapore.

Wang, J.R. 2010. The Commercial Press English and Chinese Pronouncing Dictionary - The First large Scale English-Chinese Bilingualized Dictionary. Publishing Science 4: 103-106.

Wingate, U. 2002. The Effectiveness of Different Learner Dictionaries: An Investigation into the Use of Dictionaries for Reading Comprehension by Intermediate Learners of German. Tübingen: Max Niemeyer.

Yao, N.Q. 2004. Bilingualization: Equivalence and Intercultural Communication. Chan, S.W. (Ed.). 2004. Lexicography and Translation: 109-117. Tübingen: Max Niemeyer.

Yong, H. and J. Peng. 2008. Chinese Lexicography: a History from 1046 BC to AD 1911. Oxford/New York: Oxford University Press.

Yu, W.C. 1999. Survey of the Use of English-Chinese and Chinese-English Dictionaries. Journal of Guangzhou Normal University 12: 88-93.

Zarei, A.A. 2010. The Effect of Monolingual, Bilingual and Bilingualized Dictionaries on Vocabulary Comprehension and Production. ELT Weekly 54: 17-40. Available at http://eltweekly. com/ELTWeekly_Issue_54.pdf.

Zhang, Y.H. 2010. Cognitive Semantics and Multidimensional Definition for a New Generation of Bilingual/Bilingualized Learner's Dictionaries. Journal of Foreign Language Teaching and Research 42(5): 374-379.

Zhang, Y.H. and H.M. Yong. 2007. Contemporary Lexicography. Beijing: Commercial Press.

Zöfgen, E. 1991. Bilingual Learner's Dictionaries. Hausmann, F.J. et al. (Eds.). 1989-1991: Worterbücher. Dictionaries. Dictionnaires: An International Encyclopedia of Lexicography. Vol. 3. 28882903. Berlin: De Gruyter. 